\title{
Experience Rates of Low-carbon Domestic Heating Technologies in the United Kingdom
}

Renaldi, Renaldi; Hall, Richard; Jamasb, Tooraj ; Roskilly, Anthony P.

Document Version

Final published version

Publication date:

2020

Citation for published version (APA):

Renaldi, R., Hall, R., Jamasb, T., \& Roskilly, A. P. (2020). Experience Rates of Low-carbon Domestic Heating Technologies in the United Kingdom. Copenhagen Business School [wp]. Working Paper / Department of

Economics. Copenhagen Business School No. 16-2020CSEI Working Paper No. 14-2020

Link to publication in CBS Research Portal

\section{General rights}

Copyright and moral rights for the publications made accessible in the public portal are retained by the authors and/or other copyright owners and it is a condition of accessing publications that users recognise and abide by the legal requirements associated with these rights.

Take down policy

If you believe that this document breaches copyright please contact us (research.lib@cbs.dk) providing details, and we will remove access to the work immediately and investigate your claim. 
Copenhagen

Business School

HANDELSH ØJSKOLEN

\section{Department of Economics}

Copenhagen Business School

Working paper 16-2020

\section{Experience Rates of Low-Carbon Domestic Heating Technologies in the United Kingdom}

Renaldi Renaldi

Richard Hall

Tooraj Jamasb

Anthony P. Roskilly

Department of Economics - Porcelænshaven 16A, 1. DK-2000 Frederiksberg 


\section{WORKING PAPER}

Copenhagen School of Energy Infrastructure | CSEl

\section{Experience Rates of Low-Carbon Domestic Heating Technologies in the United Kingdom}

Renaldi Renaldi

Richard Hall

Tooraj Jamash

Anthony P. Roskilly 


\title{
Experience rates of low-carbon domestic heating technologies in the United Kingdom
}

\author{
Renaldi Renaldi ${ }^{\mathrm{a}, *}$, Richard Hall ${ }^{\mathrm{b}}$, Tooraj Jamasb ${ }^{\mathrm{c}}$, Anthony P. Roskilly ${ }^{\mathrm{d}}$ \\ ${ }^{a}$ Department of Engineering Science, University of Oxford, Parks Road, Oxford OX1 3PJ, \\ $U K$ \\ ${ }^{b}$ Energy Transitions Ltd., Taffs Fall Road, Treforest Industrial Estate, Pontypridd, Cardiff \\ CF37 5TF, UK \\ ${ }^{c}$ Department of Economics, Copenhagen Business School, Porcelaenshaven 16A, 2000 \\ Frederiksberg, Denmark \\ ${ }^{d}$ Department of Engineering, Durham University, Durham DH1 3LE, UK
}

\begin{abstract}
This paper presents the experience curves of low-carbon domestic heating technologies in the United Kingdom between 2010 and 2019. The deployment of these technologies has been acknowledged as one of the main actions toward decarbonising the heating sector. In the UK, several deployment oriented policies have been implemented, such as the Renewable Heat Incentive (RHI). In this study, we focus on the following domestic heating technologies: air-source heat pumps, ground-source heat pumps, solar thermal collectors, and biomass boilers. Condensing combination gas boilers are also included to act as the baseline/incumbent technology. Using UK installation cost data for 2010 to 2019, we found that low-carbon heating technologies had experience rates of; air source heat pumps $-2.3 \pm 5 \%$, ground source heat pumps $-0.8 \pm 4 \%$, biomass boilers $0.1 \pm 2 \%$, and solar thermal $13 \pm 5 \%$, all significantly lower than the reported learning rates of similar technologies in the literature. Furthermore, we found that gas boilers have reached the floor price at approximately $£ 30 / \mathrm{kW}$. The resulting experience rates can be used in energy economics models and to inform policymakers in developing further deployment programs.
\end{abstract}

Keywords: Experience curves, Learning curves, Experience rates, Low-carbon heating, Heat decarbonisation

\section{Introduction}

Thermal energy provision in the form of heating is the largest energy end-use worldwide, but only $10 \%$ of it was supplied by renewable energy (International

\footnotetext{
${ }^{*}$ Corresponding author.

Email addresses: renaldi.renaldi@eng.ox.ac.uk (Renaldi Renaldi), anthony.p.roskilly@durham.ac.uk (Anthony P. Roskilly)
} 
Energy Agency, 2018). In the United Kingdom, heating demand accounts for around $45 \%$ of overall energy consumption and over one-third of greenhouse gas emissions (Department for Business, Energy \& Industrial Strategy, 2018). Increasing the share of low-carbon heating technologies has been one of the actions required to decarbonise the heating sector, in addition to reducing demand and improving the energy efficiency of supply and distribution (Department for Business, Energy \& Industrial Strategy, 2018). The UK government has approached this challenge by subsidising the deployment of low-carbon heating technology. Since 2011, this has been primarily achieved through the domestic Renewable Heat Incentive (RHI) and the non-domestic RHI, which made payments for the generation of low-carbon heat. The RHI replaced the Low Carbon Building Programme, which was a capital grant-based support scheme.

By focusing on 'learning-by-doing' policies for low-carbon heating technologies, it is important to address how the economies of scale and learning effects have influenced the adoption of these technologies. A widely used metric to show this is the experience rates (ER) or learning rates. The rates are derived from experience curves which illustrate the development of product price as a function of increased cumulative deployment. In energy technology, the experience rates typically depict the price reduction over cumulative installed capacity and are broadly employed in energy models to predict future trends.

Experience curve analysis has been employed to study numerous energy technologies, including electricity generation technologies (Jamasb, 2007; Rubin et al., 2015), wind turbines (Qiu and Anadon, 2012), photovoltaics (Zheng and Kammen, 2014; Elshurafa et al., 2018), electrical batteries (Schmidt et al., 2017; Kittner et al., 2017) and marine renewable energy (MacGillivray et al., 2014). The results of experience curve analyses on energy technologies have been found to be generally consistent with the results from bottom-up technology assessments (Neij, 2008).

Despite the significant challenge of decarbonising domestic heating, it has been recognised that there is relatively poor data availability on experience rates for domestic heating technologies in the UK, even for the most deployed technology, i.e. natural gas boilers (Gross and Hanna, 2019). Information on experience rates of some of the technologies has been reported in the literature for deployment in different countries at different time frames, for instance, heat pumps in Sweden and Switzerland (Kiss et al., 2014), condensing gas boilers in the Netherlands (Weiss et al., 2009), and solar water heating in the United States (Nemet, 2009). Nevertheless, due to the distributed nature of the deployment of these technologies, prices and cumulative capacity can differ significantly between countries. Therefore, the use of experience rate from one country in larger regional or global energy models is not generally recommended (Junginger and Louwen, 2020).

In this paper, we present the experience curves of four low-carbon domestic heating technologies and condensing gas boilers in the UK. The low-carbon technologies are air-source heat pumps, ground-source heat pumps, solar thermal collectors, and biomass boilers. Condensing combination gas boilers are included in the analysis as the incumbent domestic heating technology in the 
UK. The resulting experience rates are then compared with existing rates in the literature.

The paper is structured as follows. A brief overview of experience curves and low-carbon heating in the UK context are presented in Section 2. The methods and data collection procedures are explained in Section 3. The resulting experience curves and their comparison with those in the literature are given in Section 4. Finally, the conclusions and policy implications are presented in Section 5 .

\section{Background}

In this section, we provide a brief overview of experience curves, followed by the state of low-carbon domestic heating in the UK including highlights on RHI policy.

\subsection{Experience curves}

The concept of experience curves was originated within the context of technological learning. An experience curve illustrates how the costs of production will decrease as the producer accumulates more experience in manufacturing a product. In the literature, experience and learning curves are usually differentiated by the system boundary of the producer. Learning curves typically describe the costs reduction in a single company, while experience curves examine the reduction across an industry (Junginger and Louwen, 2020). Although

some studies have used the two terms interchangeably, we used the term experience curves and their corresponding experience rates in describing the empirical relation between price/cost reduction and production/installation capacity.

This empirical relation was first utilised in the technology sector for the evaluation of labour resource requirements in aeroplane manufacturing Wright (1936), and developed further by Boston Consulting Group (1970). The experience curve can be described with Eq. 1.

$$
P(x)=A X^{-b}
$$

In the context of energy technology, the terms in Eq. 1 can be described as follows: $P(x)$ represents the price of the equipment $(£ / \mathrm{kW})$ at a cumulative installed capacity $X(\mathrm{GW})$. The normalisation factor or the price of the first unit $A(£ / \mathrm{kW})$ and the experience index $b$ are derived with a regression analysis of the logarithmic function of Eq. 1. The experience rate (ER) is then calculated based on Eq. 2.

$$
E R=1-2^{-b}
$$

This rate shows how much the product cost decreases for every doubling of cumulative production. For instance, Schmidt et al. (2017) have identified an ER value of $16 \%$ for Lithium-ion batteries in electric vehicles application, which indicates that a $16 \%$ decline in price has been observed and is expected 
for every doubling of cumulative production of the batteries. Clearly, the price reduction rate of technology will change and stop as the technology matures. The change in the price reduction rate can be captured by using non-constant experience rates, as shown by Wei et al. (2017) for ballasts, lightings, fuel cells, and solar photovoltaic. Furthermore, the stopping of the price reduction rate can be included in the curve by including floor costs. For example, materials costs were used to set the floor costs in a two-stage learning curve of EV batteries (Hsieh et al., 2019).

The applications of experience curves can be categorised into direct and indirect applications (Junginger and Louwen, 2020). In direct applications, experience curves can be used as a tool for forecasting future cost developments and quantifying the required interventions for technologies to achieve price competitiveness. Forecasting the future cost is typically useful for emerging technologies, such as energy storage Kittner et al. (2017); Schmidt et al. (2017). In quantifying the required interventions to reduce cost, experience curves can also be used to identify historical patterns of policies-influenced cost reduction. For instance, Van Buskirk et al. (2014) performed a retrospective study using experience curves of domestic appliances and suggested that energy efficiency policies may have a positive impact on the reduction of cost.

The indirect applications of experience curves involve the inclusion of experience rates in energy systems and integrated assessment models. The rates are typically employed to include the change in technology cost over time. Examples of energy and assessment models that used experience curves include IPCC (IPCC, 2013), ESO-XEL (Heuberger et al., 2017), and FTT:Heat (Knobloch et al., 2019). The latter simulated the decarbonisation of domestic heating and implemented endogenous cost reductions model with constant learning rates for different heating technologies.

\subsection{Low-carbon heating in the UK}

The last domestic space and hot water heating transition in the UK happened in the 1960s and 1970s with the switching of heating fuel from town gas made from coal to natural gas (Sovacool and Martiskainen, 2020). Since then, natural gas via a nation-wide gas grid has been the main domestic heating fuel with a relatively consistent market share of $75-80 \%$ between 1990 and 2017 (Fig. 1).

In 2008, the UK government introduced the Climate Change Act which aims for $80 \%$ greenhouse gas reduction target relative to 1990 levels by 2050 (Parliament of the United Kingdom, 2008). The goal of this legislation has been updated recently by introducing a net-zero target for at least a $100 \%$ greenhouse gasses emissions reduction in the UK by 2050 (Parliament of the United Kingdom, 2019). In order to reach this goal, it has been suggested that no fossil fuel-based heating systems can be installed after 2035 (Committee on Climate Change, 2019).

The required heating transition from natural gas to low-carbon heating faces substantial financial challenges due to the relatively low cost of natural gas (Eurostat, 2020). Given the relatively low cost of natural gas in the UK and 


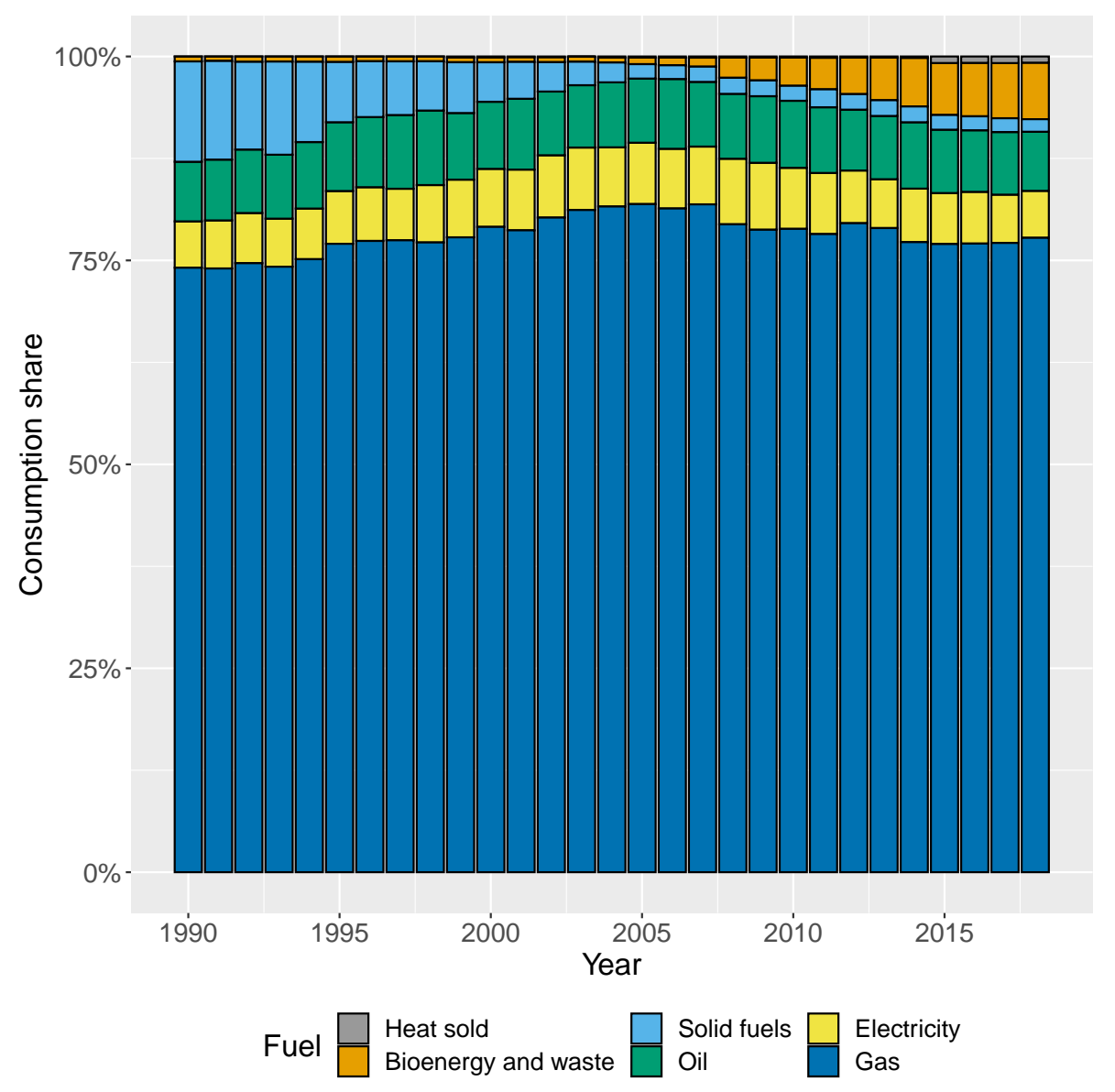

Figure 1: Fuel shares for space and domestic hot water heating in the UK (1990-2018) (Department for Business, Energy \& Industrial Strategy, 2019). 
the capital costs associated with the purchase of low carbon heating technologies, government subsidies are required to make them economically competitive with the incumbent technology. Several policies supporting low-carbon heating have been introduced since 2000, such as the Community Renewables Initiative, Biomass Heat Accelerator, Low Carbon Buildings Programme, and the Green Deal (Connor et al., 2015). In 2011, the UK government introduced the Non-Domestic RHI as a tariff mechanism dedicated to foster the deployment of renewable heating technologies. This was followed by the Domestic RHI in 2014.

\subsubsection{Renewable Heat Incentive (RHI)}

Domestic RHI aims to encourage the use of renewable heat by providing seven years of payments for participants with eligible heating technology (Ofgem, 2020). The supported heating technology types for Domestic RHI are biomass boilers (boilers and pellet stoves), air source heat pumps, ground source heat pumps, and solar thermal collectors (flat plate and evacuated tube). The heating equipment must be certified by the Microgeneration Certification Scheme (MCS). Each renewable heating equipment is limited to $45 \mathrm{~kW}$ thermal capacity, while a combined system is limited to $70 \mathrm{~kW}$. Furthermore, biomass boilers and heat pumps must provide space heating or space and domestic hot water (DHW) heating, while solar thermal can only be used for DHW heating.

Domestic RHI payments are calculated based on the heat demand estimate on the Energy Performance Certificate of the dwelling or for solar thermal, based on the estimated annual generation figure on the MCS certificate. The tariffs are dependent on the technology and have been modified since the inception of the RHI. Fig. 2 shows the development of domestic RHI tariffs (Ofgem, 2020).

The RHI has been widely studied from various viewpoints in the literature. Detailed historical development of the RHI, including its early stage performance, can be found in Connor et al. (2015). The socio-political interactions in the development of RHI have also been analysed (Lowes et al., 2019). Technology-specific studies on the impact of RHI include its potential benefit in a residential air-source heat pump (Renaldi et al., 2017), the financial challenge for solar thermal application (Abu-Bakar et al., 2014), and the incentivisation of biomass boilers installation (Nasiri et al., 2016). Furthermore, the RHI tariff has also been included in the analysis of applications that are currently not eligible for the incentive, such as hybrid photovoltaic-thermal collectors (Herrando and Markides, 2016) and solar district heating (Renaldi and Friedrich, 2019).

\subsubsection{Heating technologies under consideration}

In this paper, we focused on the four RHI-eligible low-carbon domestic heating technologies and condensing gas boilers as the incumbent technology. They are briefly described as follows:

- Air-source heat pumps (ASHP) consist of an electricity-driven cycle that transferred thermal energy from the ambient air into the heated space/water. Only air-to-water ASHP is eligible for Domestic RHI. 


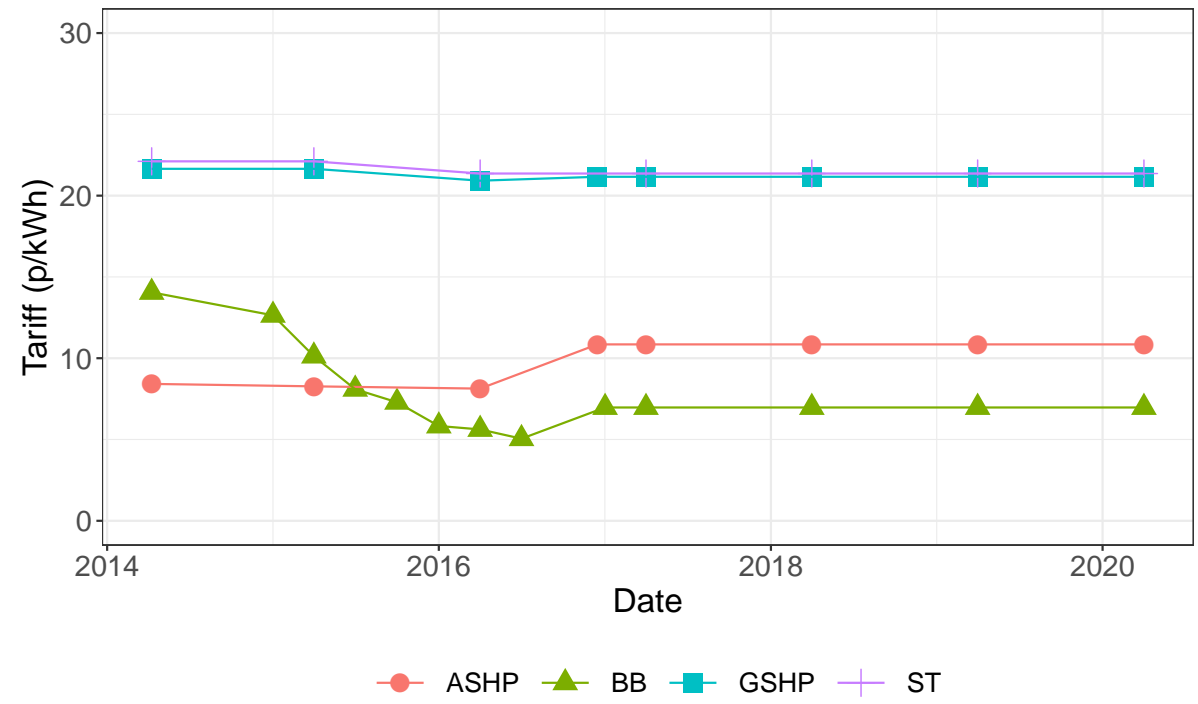

Figure 2: Tariffs development of Domestic RHI (April 2014 - April 2020) (Ofgem, 2020). ASHP: Air source heat pumps; BB: Biomass boilers; CGB: Condensing gas boilers; GSHP: Ground source heat pumps; ST: Solar thermal.

- Ground-source heat pumps (GSHP) use the same cycle as the air-source counterpart but transferring the thermal energy from the ground rather than the ambient air.

- Solar thermal (ST) collectors convert solar radiation from the sun into thermal energy to heat the working fluid which then transfers the collected energy to the heated domestic hot water.

- Biomass boilers (BB) perform combustion or gasification of biomass fuels (wood log, chips, or pellets) and transfer the thermal energy to the heated space and domestic hot water.

- Condensing gas boilers (CGB) use the thermal energy from natural gas combustion to heat the space and DHW through a water circuit. Furthermore, waste heat from the exhaust gas is recovered and in effect, condensing the outlet water vapour and increasing the boiler efficiency.

\section{Method and data}

The experience curves and experience rates were derived by applying Eq. 1 and 2 on the collated price/costs and cumulative capacity data. The base currency used in this study is Great British Pound sterling (£), while the base year is 2019. Furthermore, the experience rate uncertainty is estimated by calculating the $95 \%$ confidence interval based on the mean and standard error.

The required data in constructing experience curves are costs data and cumulative installed capacity data. Two types of costs were used in this study: 
equipment price and total installation costs. The equipment price data were collected from two main sources: (i) Price lists from manufacturers and distributors, and (ii) Listed prices from online heating equipment stores. The latter is combined with the Wayback Machine tool from the Internet Archive to obtain historical prices data (The Internet Archive, 2019). Basic equipment price data were considered, i.e. without additional accessories or package options, unless stated otherwise. The reported prices were without the value-added tax (VAT).

The total installation costs were gathered from the Microgeneration Certification Scheme (MCS) installations database. MCS provides assessment certificate as a part of RHI application in the UK. The data are the reported information from the consumer or installer of the low-carbon heating technologies. The total installation costs include equipment and installation costs. All price data were adjusted to the base year (2019) value of pound sterling (Bank of England, 2019).

In order to compare with the UK experience curves, we reproduced available experience curves of the considered technologies from the literature. In converting the price into our base currency year, we first deflated the historical price to the base year and then converted the currency based on the conversion rate in the base year (Jakob et al., 2020). Due to the lack of available experience curves of biomass boilers from other countries, we constructed one based on the equipment price and deployment in Germany. We collected equipment price data with the aforementioned method, while the deployment data were gathered from the Bioenergy Europe Statistical Report 2019 (Bioenergy Europe, 2019). Furthermore, the biomass boilers capacity in Germany case was limited to between 20 and $30 \mathrm{~kW}$ because of the lack of continuation of price data over the range of capacity. This range also corresponds to the average installed capacity of $25 \mathrm{~kW}$.

The collated data and their references are available in the Supplementary Information.

\section{Results and discussion}

The resulting experience curves are illustrated in Fig. 3. Experience curves based on equipment price are shown in Fig. 3a, while those based on total installation costs are shown in Fig. 3b.

From Fig. 3a, it is clear that the installed capacity of low-carbon heating technologies is two order of magnitudes lower than the incumbent CGB. The price of these technologies are also significantly higher than the gas boilers, with the cost of ASHP, GSHP, and ST between approximately $400-1000 £ / \mathrm{kW}$ compared to $30 £ / \mathrm{kW}$ of CGB. Unlike the other low-carbon technologies, BB have a lower price at approximately $170 £ / \mathrm{kW}$. In terms of the experience rate, ASHP and ST have the largest among low-carbon technologies, followed by BB and GSHP. However, the margin of error for ST is significantly larger than the rest. This is related to the data availability and explored further in Section 4.2.

The growth of cumulative capacity for low-carbon technologies follows a similar trend. In the first half (2010-2014), annual installations were growing 


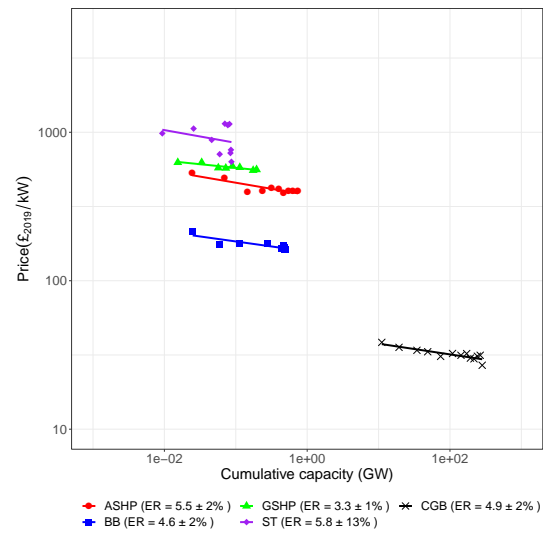

(a)

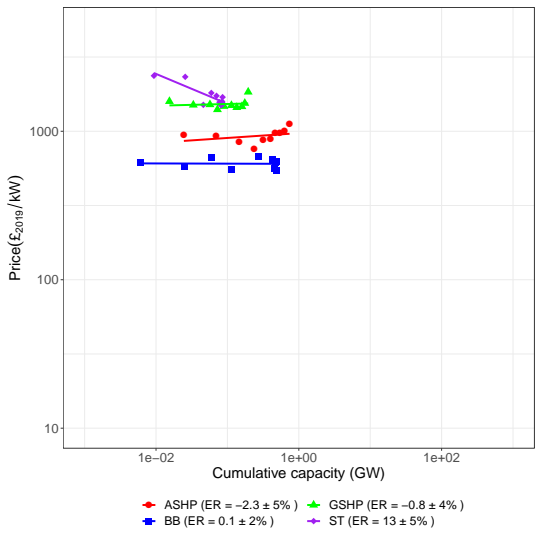

(b)

Figure 3: Experience curves of the domestic heating technologies in the UK based on: (a) equipment price, and (b) total installation costs. All data points are from 2010 to 2019, apart from CGB (2004-2016). The experience rates are shown between brackets in the legend as the rate and standard error. Both $\mathrm{x}$ - and $\mathrm{y}$-axis are in logarithmic scale.

rapidly for every technology. However, the annual installations were significantly slowing down in the second half period (2015-2019).

Experience curves derived from total installation costs are mostly different than those from equipment prices (see Fig. 3b). Here, ASHP and GSHP have negative rates, while ST has significantly larger rates. A negative experience rate corresponds to the lack of cost reduction as the deployment increases. Furthermore, CGB were not plotted due to unavailability of historical total installation costs.

In the following sections, a more detailed assessment of each technology is described. Comparison with ER from other studies is also given and discussed further.

\subsection{Air- and ground-source heat pumps}

Experience rate of $5.5 \%$ and $-2.3 \%$ have been identified for ASHP based on equipment price and total installation costs, respectively (Fig. 3). For GSHP, the rates are $3.3 \%$ and $-0.8 \%$ for equipment price and total installations costs, respectively. These values are significantly smaller than most reported rates in the literature. For instance. experience rate of 30\% was assumed for both ASHP and GSHP in a recent study of simulating deep decarbonisation of residential heating (Knobloch et al., 2019).

In the case of ASHP, the equipment price has been reduced by $24 \%$ in the past decade, while the cumulative capacity grows from $0.02 \mathrm{GW}$ in 2010 to 0.74 $\mathrm{GW}$ in 2019. The price reduction of GSHP is lower at $10 \%$, while their capacity increases from 0.015 to $0.2 \mathrm{GW}$. The gap between the ASHP and GSHP curves is larger in Fig. 3b than Fig. 3a because the total installation costs include the substantial cost of the ground heat exchanger. 
From the comparison between Fig. 3a and $3 \mathrm{~b}$ for ASHP and GSHP, the trend of reduction in equipment price but not on total installation costs implies an increasing trend in installation costs, i.e. total installation costs minus equipment capital costs.

Fig. 4 illustrates the difference between the constructed UK GSHP experience curves with the case of Switzerland and Sweden (Kiss et al., 2014). The Swiss and Swedish data span over a longer timeline than the UK case. The Switzerland case has a relatively large experience rate at $20 \%$ with capacity growth over two orders of magnitude. However, it is interesting to note that despite the similar capacity growth, the experience rate in Sweden is only $1.8 \%$. A recent study shows that the normalised price of GSHP in Sweden has been increasing by $29 \%$ between 2008-2020 (Gidén Hember, 2020). The price reduction in Switzerland was attributed to economies of scale of both heat pumps and borehole heat exchanger and technological improvements of the components (Kiss et al., 2014; Jakob et al., 2020). On the other hand, the lack of large price reduction and even increasing price in Sweden has been attributed to limited competition, lack of stability in subsidies, domestic production, and more expensive components and additional features (Kiss et al., 2014; Gidén Hember, 2020).

Despite the lack of significant price reduction, the number of heat pumps installation in Sweden is still very high relative to Switzerland and the UK. In 2018, the number of heat pump units sold per 1000 households in Sweden was 22.7, while the figure was 8.6 and 0.78 for Switzerland and the UK, respectively (European Heat Pump Association, 2020). In addition to capital cost, the market growth of heat pumps in Sweden has been attributed to the more energy-efficient alternative to the previous incumbent direct electric heating, the complementarity of heat pumps with existing technologies, the introduction to technical standards, installer certification training, and supportive building regulations (Gross and Hanna, 2019).

The low ER value for both ASHP and GSHP in the UK could be attributed to several factors. The installation rate of heat pumps after the introduction of Domestic RHI has been lower than expected, which could lead to a lack of competition between installers. They have been demonstrated to have a strong influence on the uptake and performance of ASHP in the UK (Hanna et al., 2018). Another factor that has been shown to negatively impact the deployment of heat pumps in the UK is the current balance of tax and regulatory costs through the fuel costs, i.e. electricity and natural gas (Barnes and Bhagavathy, 2020).

\subsection{Solar thermal collectors}

Solar thermal collectors in the UK have experienced a reduction in both equipment price and total installation costs in the 2010-2019 period as the capacity grew almost ten-fold from 9 to $86 \mathrm{MW}$ (Fig. 3). The equipment pricebased ER is close to 6\%, while the total installation costs-based ER is $13 \%$, with both values having a relatively large standard error. The potential sources 


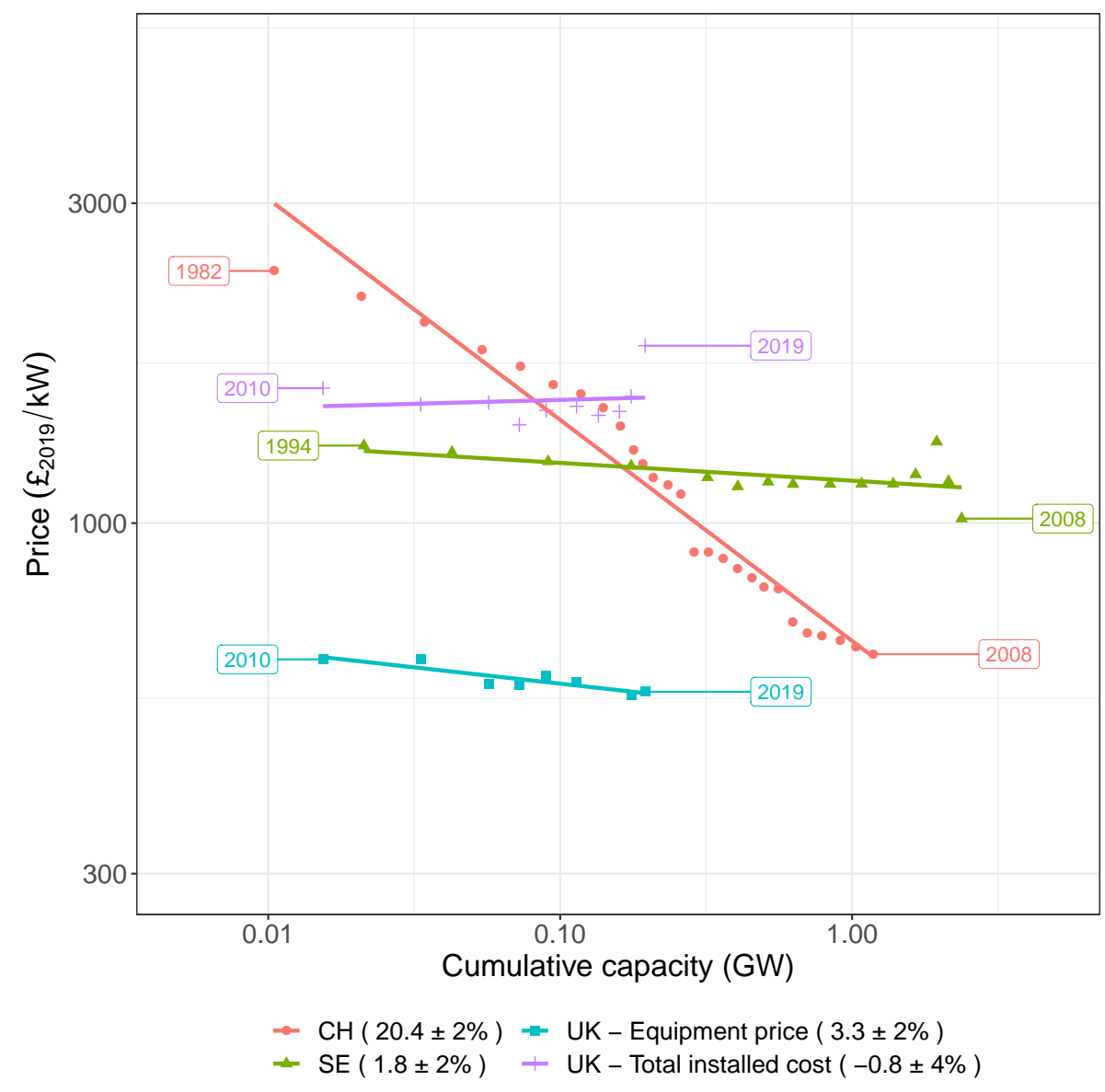

Figure 4: Comparison between the experience curves of ground source heat pumps in the UK, Switzerland (CH), and Sweden (SE). Deployment and price data for Switzerland and Sweden were taken from Kiss et al. (2014). 
of this error are: (i) the types of collectors considered, and (ii) the variability of collected data.

First, both the equipment price and total installation costs data include flat plate collectors (FPC) and evacuated tube collectors (ETC). Although it is possible to differentiate the two in the equipment price data, this is not possible in the case of total installation costs. Differentiating the two collectors in equipment price-based ER calculations yields ER of $-2 \pm 10 \%$ and $3 \pm 10 \%$ for FPC and ETC, respectively. Second, the variability of collected historical price data contributes negatively to the produced curves and ER. For example, the errors of the previously calculated ER for FPC and ETC are still relatively high at $10 \%$. This can be attributed to the year to year variance of available historical price data. Such variability could also explain the standard error in the total installation costs-based ER of ST since the proportion of installations between FPC and ETC might differ from year to year.

In order to compare the calculated ER with available values in the literature, experience curves of solar thermal systems in the US and Germany are shown alongside the UK curves in Fig. 5. The curves from Germany are for domestic hot water (DHW)-only systems and combi systems (space heating and DHW), while the US case is for DWH-only systems. Both German and US case considered capital cost per system, e.g. it includes storage cost in Germany. Furthermore, the cumulative capacity in the case of Germany was based on installed capacity in the European Union and no distinction was made between the capacity of DHW and Combi system.

In Germany, ER values close to $18 \%$ and $8 \%$ were calculated for DHW and combi systems, respectively. A negative ER of $-3.2 \%$ was calculated for ST systems in the US between 1973-2004, despite the significant capacity growth over the period (Nemet, 2009). The increasing price was due to increases in the materials and labour costs rather than technical improvements (Taylor et al., 2007).

The RHI limited the solar thermal market to domestic hot water, which may have limited the potential cost reductions, as larger space heating systems have lower capital costs per kW installed (Weiss and Spörk-Dür, 2017).

\subsection{Biomass boilers}

The cumulative installed capacity of domestic biomass boilers in the UK has grown from approximately $6 \mathrm{MW}$ in 2010 to $0.5 \mathrm{GW}$ in 2019. The calculated ER values are $4.6 \%$ and $0.1 \%$ for equipment price- and total installation costs-based, respectively.

The lack of total installation costs reduction over the years can be attributed to several potential reasons. First, the data used to construct the BB curve in Fig. 3b did not differentiate between different types of biomass boilers. This could have a significant impact since there are major differences in equipment price and total costs between boilers with different fuel types, i.e. wood pellets, logs, and chips, and integrated accessories, e.g. fuel storage and feed-in systems. Second, due to its relative maturity even among the low-carbon technologies, it 


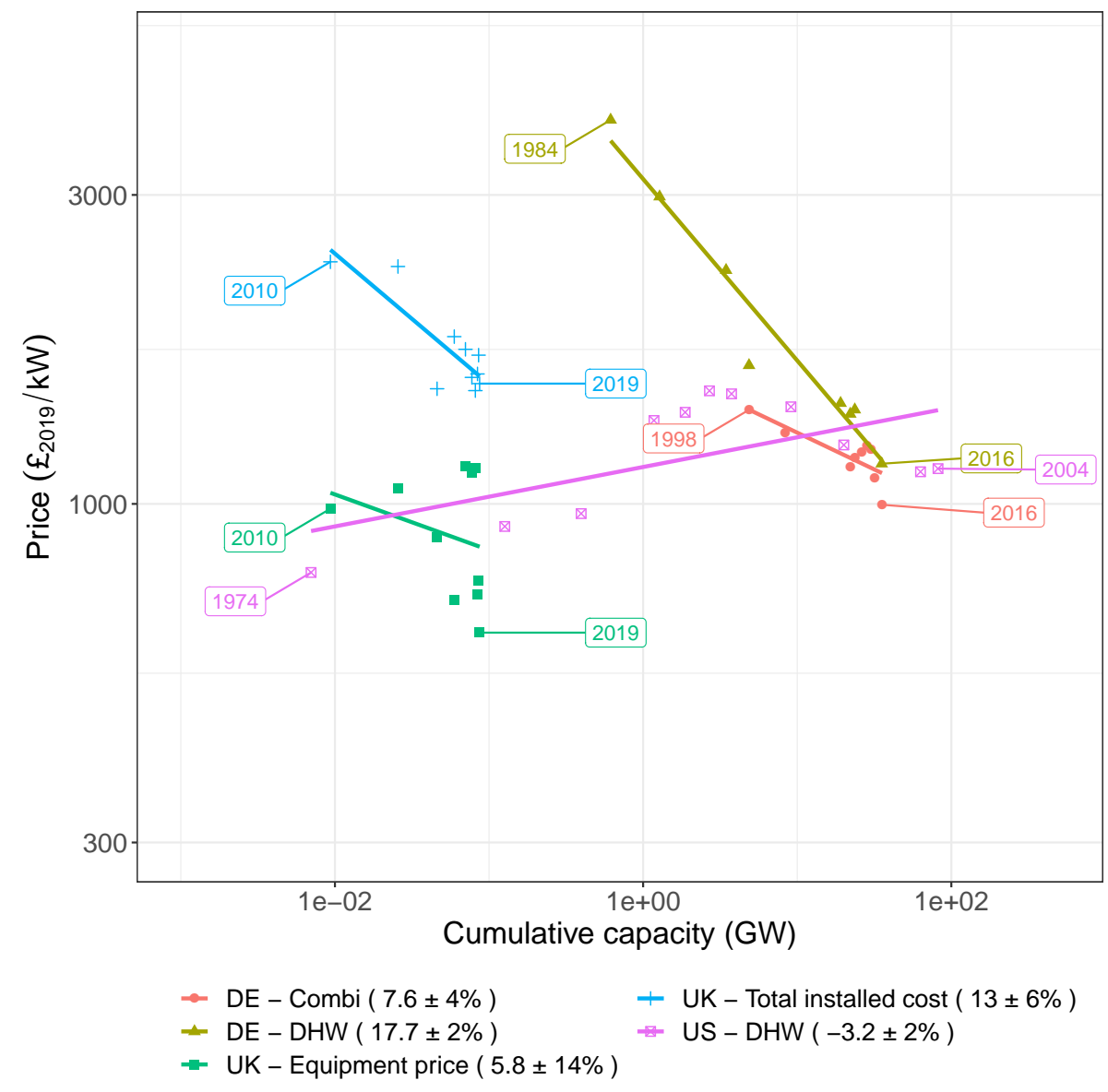

Figure 5: Comparison between the experience curves of solar thermal systems in the UK, US, and Germany (DE). Deployment and price data for US and Germany were taken from Nemet (2009) and Orozaliev et al. (2017), respectively. 
is possible that there has been simply no learning effect in the total installation costs from the increase in cumulative capacity for the case of biomass boilers in the UK. This suggestion can be examined further by looking at the equipment price-based ER for biomass boilers.

ER value of $4.6 \%$ for BB shown in Fig. 3a was calculated based on all fuel type in the gathered historical price data. Once the data were differentiated between fuel types, the ER value is $4 \pm 4 \%$ and $2.3 \pm 4 \%$ for $\log$ and pellet boilers, respectively. Therefore, the lower ER of wood pellets boilers could contribute to the lack of reduction in total installation costs since wood pellets have the largest share among different biomass fuels in RHI accredited applications (Adams and Lindegaard, 2016).

Both UK BB curves are shown along the constructed Germany BB curve in Fig. 6. The price and installation data in the Germany case are limited to wood pellets boilers. It can be seen that there is also a lack of price reduction in the case of wood pellets boilers in Germany.

\subsection{Condensing combi gas boilers}

As the incumbent domestic heating technology in the UK, condensing gas boilers have a cumulative installed capacity of over $100 \mathrm{GW}$ and a normalised price of approximately $30 £ / \mathrm{kW}$, as illustrated in Fig. 3a. The relatively low price and ER value of $4.9 \%$ demonstrate the maturity of the technology. The share of condensing gas boilers installation for domestic heating in the UK has been growing from around $2 \%$ in 2000 to nearly $75 \%$ in 2017 of all installed domestic gas boilers (Department for Business, Energy \& Industrial Strategy, 2019), as shown in Fig. 7. This significant growth was an implication of a 2004 regulation in the UK which enforce the installation of high-efficiency condensing gas boilers in all new gas central heating system.

Comparison between the UK and Netherlands for CGB is shown in Fig. 8. The data for the Netherlands were adopted from Jakob et al. (2020). The significantly larger ER in the Netherlands case, $13 \%$ against $4.9 \%$ for the UK, is due to longer time span and larger capacity growth. The price reduction in the Netherlands has been attributed to economies of scale, increased specialization and automation of the production process, and outsourcing of production to low-wage regions (Weiss et al., 2009; Jakob et al., 2020). As shown in Fig. 8, the prices in the Netherlands in recent years are close to the price range in the UK at around $30-40 £ / \mathrm{kW}$. This illustrates the regional nature of CGB manufacturers where significant numbers of European manufacturers marketed their products in both the UK and Netherlands.

\subsection{Study limitations}

One of the main limitations of the study is the lack of comprehensive historical data on both price/costs and installed capacity for different domestic heating technologies in the UK. Data availability is indeed a common issue in experience curve assessments. For instance, heat pumps have been identified as a technology that has been deployed for decades, including for cooling, 


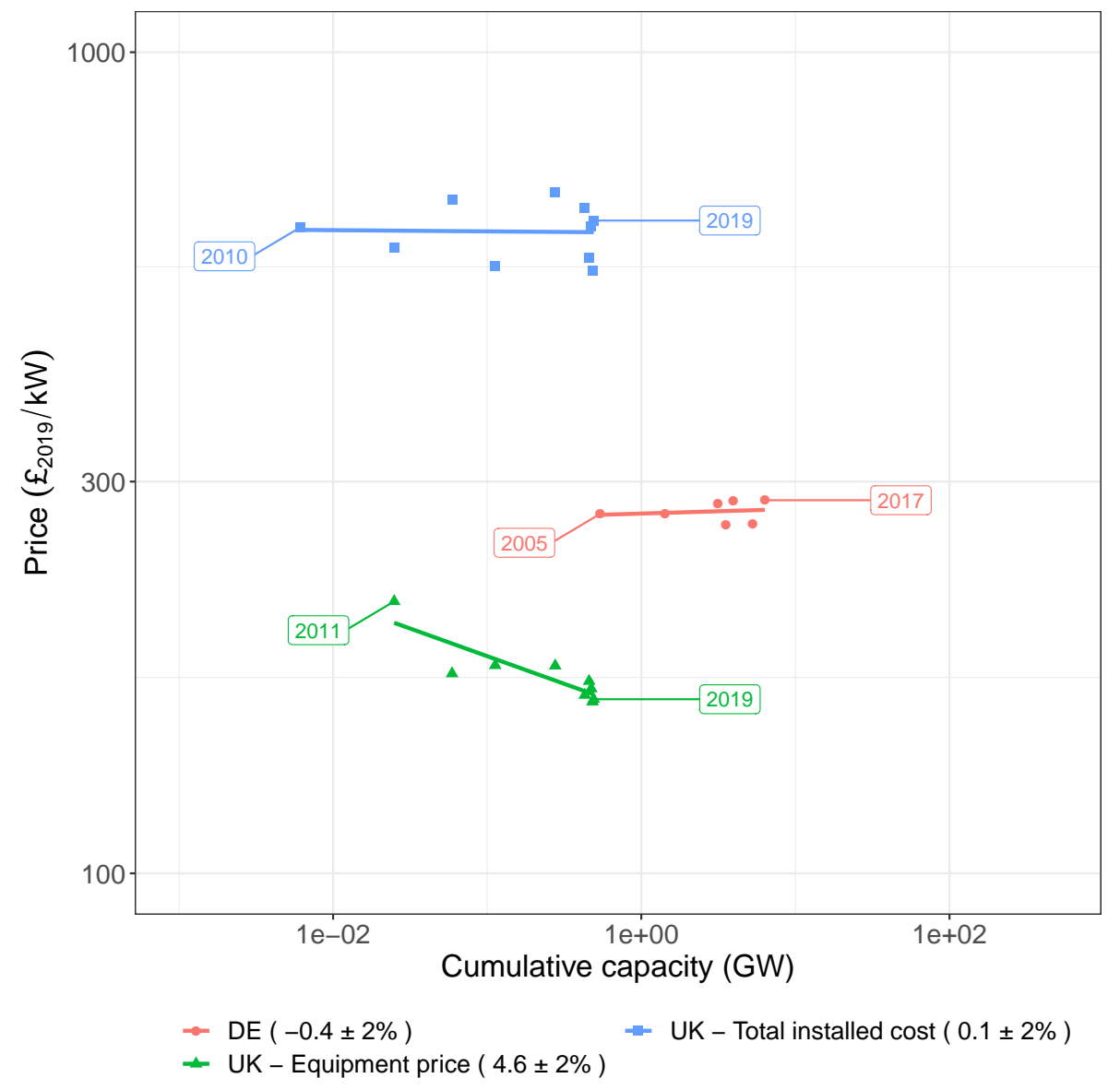

Figure 6: Comparison between the experience curves of biomass boilers in the UK and Germany (DE). 


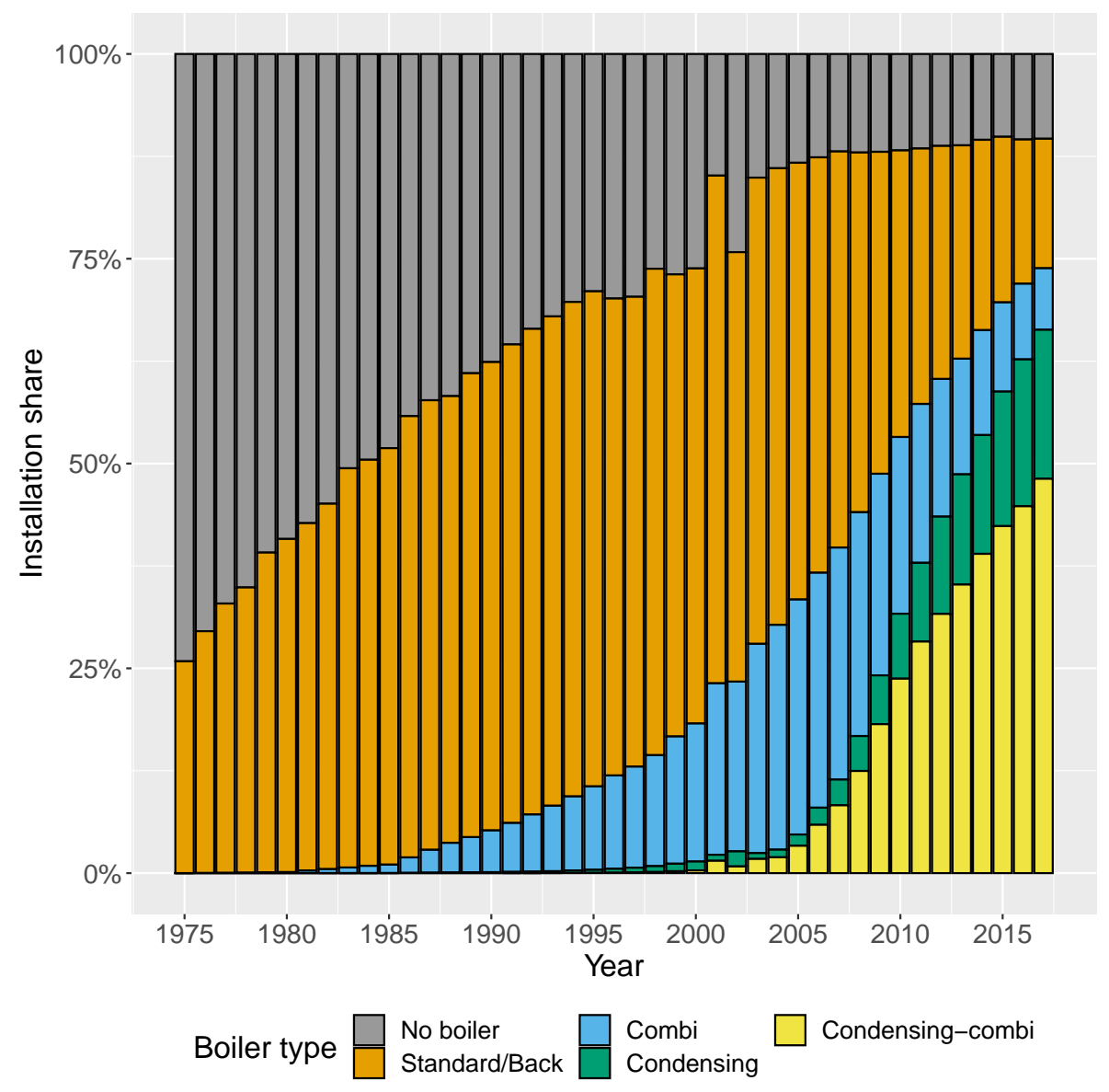

Figure 7: Shares of different boiler types installed in UK domestic dwellings (Department for Business, Energy \& Industrial Strategy, 2019). 


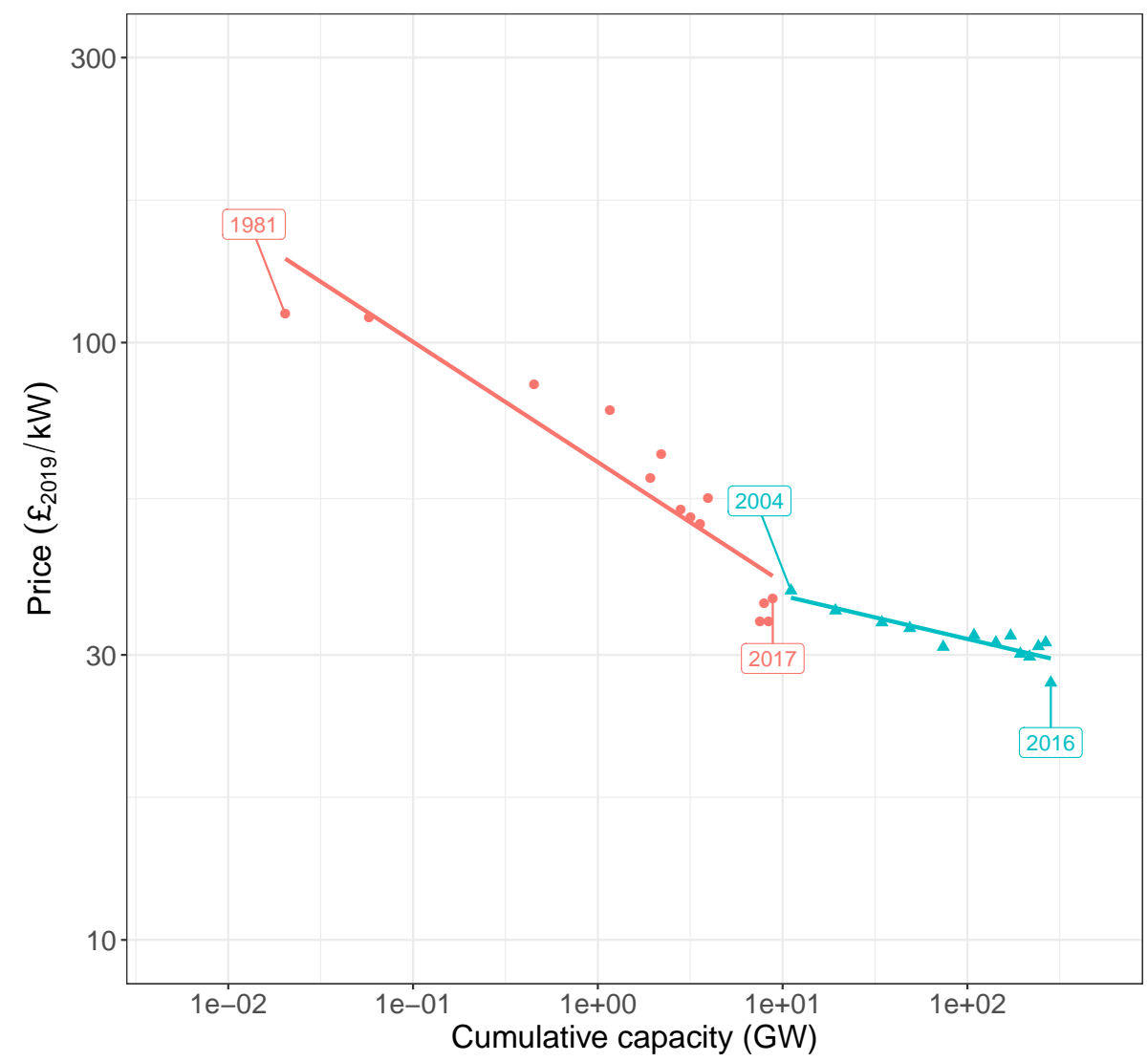

$=\mathrm{NL}(13 \pm 2 \%)-\mathrm{UK}(4.9 \pm 2 \%)$

Figure 8: Comparison between the experience curves of condensing gas boilers in the UK and Netherlands. Deployment and price data for Netherlands were taken from Jakob et al. (2020). 
and acknowledged as a key heating technology in decarbonised energy systems, yet systematic data collection for their costs and performance has been sparse in comparison with, for instance, solar photovoltaics (Junginger and Louwen, 2020). In this study, we have made efforts to overcome this data availability challenge by collating historical prices through numerous sources, such as price lists and online stores, as well as using reliable installed capacity data from the MCS installation database.

In comparing the UK curves with those in the literature, the influence of currency exchange should be considered in interpreting the comparative analysis. The effect of exchange rate fluctuations and a method to correct the effect have been described for the case of large-scale photovoltaic plants (Lilliestam et al., 2020). Nevertheless, the method was proposed for a global experience rate, and thus less applicable for local rates focused in this study. Moreover, the lack of information on the global deployment of low-carbon heating technologies would also be a major hindrance. In order to minimise the effect of the exchange rate, we followed recommendations from Junginger and Louwen (2020), where the price data were deflated at a national scale on original currency and then converted to the base currency using the conversion rate of the base year.

\section{Conclusions and policy implications}

Despite the importance of low-carbon heating technologies in the effort towards decarbonising heat, information on their experience rates in the UK are still scarce. This study presents experience curves and experience rates of lowcarbon domestic heating technologies and condensing gas boilers in the UK. We identify five insights from developing the UK experience curves and comparing them with curves from other countries.

First, the experience rates of low-carbon heating technologies in the UK are relatively low for equipment price-based rates, and even negative for heat pumps in the total installation costs-based rates. The former is expected due to the maturity of these technologies and the global nature of manufacturing companies in the field. The latter, however, should be subjected to further examination in order to achieve better-supporting policies for further deployment of the technologies. Therefore, policymakers will need to consider the implications of the capital costs of domestic low-carbon heat technologies not being economically competitive against condensing combi gas boilers anytime in the near future.

Second, the importance of installation costs in driving the total costs trend has been identified by comparing the experience curves derived from equipment price and total installation costs. Although all heating technologies have experienced equipment price reduction, it is not the case for their total installation costs. Unlike conventional large consumer appliances, the installation of domestic heating technologies and their respective costs are highly varied.

Third, even if the total installation costs do not change significantly, there can still be positive impacts in deployment rates through supporting innovation in technological performance, fuel cost reductions, and business models. Furthermore, not all progress is translated into cost reduction, as it can be quality 
improvements or regulatory standards that may even increase the cost, as illustrated by the case of ground source heat pumps in Sweden. In the UK, several options include, for example, dynamic electricity pricing and a more stringent installation standard for heat pumps.

Fourth, the experience rate of condensing gas boilers is relatively low at around 5\%. As the incumbent technology, condensing gas boilers have a small but steady decline in product price while deployment grows from 10 to $100 \mathrm{GW}$. The price of condensing gas boilers has potentially arrived at the floor price of $30 £ / \mathrm{kW}$.

Finally, the comparison between experience curves in the UK and other countries reveal a relatively high variation for given heating technology. For distributed products like domestic heating technologies, experience rates are highly dependent on geographical location. Thus, the use of global experience rates in simulating a specific country should be avoided.

\section{Acknowledgements}

The study was supported by the EPSRC Centre for Energy Systems Integration (EP/P001173/1). The authors are grateful for the access provided to the MCS Installation Database.

\section{References}

Abu-Bakar, S.H., Muhammad-Sukki, F., Ramirez-Iniguez, R., Munir, A.B., Yasin, S.H.M., Mallick, T.K., McLennan, C., Rahim, R.A., 2014. Financial analysis on the proposed renewable heat incentive for residential houses in the united kingdom: A case study on the solar thermal system. Energy policy $65,552-561$.

Adams, P., Lindegaard, K., 2016. A critical appraisal of the effectiveness of uk perennial energy crops policy since 1990. Renewable and Sustainable Energy Reviews 55, 188-202.

Bank of England, 2019. Inflation calculator — Bank of England. URL: https://www.bankofengland.co.uk/monetary-policy/inflation/ inflation-calculator. accessed: 2019-06-11.

Barnes, J., Bhagavathy, S.M., 2020. The economics of heat pumps and the (un) intended consequences of government policy. Energy Policy 138, 111198.

Bioenergy Europe, 2019. Bioenergy Europe Statistical Report 2019: Report Pellet. URL: https://bioenergyeurope.org/article/ 101-statistical-report-2019.html. accessed: 04-08-2020.

Boston Consulting Group, 1970. Perspectives on Experience. 
Committee on Climate Change, 2019. Net Zero: The UK's contribution to stopping global warming. URL: https://www.theccc.org.uk/publication/ net-zero-the-uks-contribution-to-stopping-global-warming/.

Connor, P.M., Xie, L., Lowes, R., Britton, J., Richardson, T., 2015. The development of renewable heating policy in the United Kingdom. Renewable Energy 75, 733-744.

Department for Business, Energy \& Industrial Strategy, 2018. Clean Growth - Transforming Heating. URL: https://www.gov.uk/government/publications/ heat-decarbonisation-overview-of-current-evidence-base. Accessed: 24-08-2020.

Department for Business, Energy \& Industrial Strategy, 2019. Energy consumption in the UK. URL: https://www.gov.uk/government/statistics/ energy-consumption-in-the-uk. accessed: 04-08-2020.

Elshurafa, A.M., Albardi, S.R., Bigerna, S., Bollino, C.A., 2018. Estimating the learning curve of solar pv balance-of-system for over 20 countries: Implications and policy recommendations. Journal of Cleaner Production 196, $122-134$.

European Heat Pump Association, 2020. EHPA Stats. URL: www. stats .ehpa . org. Accessed: 25-08-2020.

Eurostat, 2020. Natural gas price statistics. URL: https://ec.europa. eu/eurostat/statistics-explained/index.php?title=Natural_gas_ price_statistics. Accessed: 24-08-2020.

Gidén Hember, A., 2020. Understanding Green Energy Technology: Learning Processes in the Development of the Ground Source Heat Pump. Master's thesis. Uppsala Universitet. Uppsala, Sweden.

Gross, R., Hanna, R., 2019. Path dependency in provision of domestic heating. Nature Energy , 1.

Hanna, R., Leach, M., Torriti, J., 2018. Microgeneration: The installer perspective. Renewable Energy 116, 458-469.

Herrando, M., Markides, C.N., 2016. Hybrid PV and solar-thermal systems for domestic heat and power provision in the UK: Techno-economic considerations. Applied Energy 161, 512-532.

Heuberger, C.F., Rubin, E.S., Staffell, I., Shah, N., Mac Dowell, N., 2017. Power capacity expansion planning considering endogenous technology cost learning. Applied Energy 204, 831-845.

Hsieh, I.Y.L., Pan, M.S., Chiang, Y.M., Green, W.H., 2019. Learning only buys you so much: practical limits on battery price reduction. Applied Energy 239, 218-224. 
International Energy Agency, 2018. Renewables 2018: Analysis and Forecasts to 2023. Technical Report. International Energy Agency.

IPCC, 2013. in: Stocker, T. F., et al., (Eds.), IPCC AR5 WG1 Climate Change 2013: The Physical Science Basis. Working Group 1 (WG1) Contribution to the Intergovernmental Panel on Climate Change (IPCC) 5th Assessment Report (AR5), Cambridge University Press.

Jakob, M., Reiter, U., Krishnan, S., Louwen, A., Junginger, M., 2020. Heating and cooling in the built environment, in: Technological Learning in the Transition to a Low-Carbon Energy System. Elsevier, pp. 189-219.

Jamasb, T., 2007. Technical change theory and learning curves: patterns of progress in electricity generation technologies. The Energy Journal 28, 5172 .

Junginger, M., Louwen, A., 2020. Technological Learning in the Transition to a Low-Carbon Energy System: Conceptual Issues, Empirical Findings, and Use, in Energy Modeling. Academic Press.

Kiss, B., Neij, L., Jakob, M., 2014. Heat pumps: A comparative assessment of innovation and diffusion policies in Sweden and Switzerland, in: Grubler, A., Wilson, C. (Eds.), Energy Technology Innovation: Learning from Historical Successes and Failures. Cambridge University Press, New York. chapter 9, pp. $118-132$.

Kittner, N., Lill, F., Kammen, D.M., 2017. Energy storage deployment and innovation for the clean energy transition. Nature Energy 2, 17125.

Knobloch, F., Pollitt, H., Chewpreecha, U., Daioglou, V., Mercure, J.F., 2019. Simulating the deep decarbonisation of residential heating for limiting global warming to 1.5 c. Energy Efficiency 12, 521-550.

Lilliestam, J., Melliger, M., Ollier, L., Schmidt, T.S., Steffen, B., 2020. Understanding and accounting for the effect of exchange rate fluctuations on global learning rates. Nature Energy 5, 71-78.

Lowes, R., Woodman, B., Fitch-Roy, O., 2019. Policy change, power and the development of great britain's renewable heat incentive. Energy Policy 131, $410-421$.

MacGillivray, A., Jeffrey, H., Winskel, M., Bryden, I., 2014. Innovation and cost reduction for marine renewable energy: A learning investment sensitivity analysis. Technological Forecasting and Social Change 87, 108-124.

Nasiri, F., Mafakheri, F., Adebanjo, D., Haghighat, F., 2016. Modeling and analysis of renewable heat integration into non-domestic buildings-the case of biomass boilers: A whole life asset-supply chain management approach. Biomass and bioenergy 95, 244-256. 
Neij, L., 2008. Cost development of future technologies for power generation - a study based on experience curves and complementary bottom-up assessments. Energy Policy 36, 2200-2211.

Nemet, G.F., 2009. Interim monitoring of cost dynamics for publicly supported energy technologies. Energy Policy 37, 825-835.

Ofgem, 2020. Domestic Renewable Heat Incentive (RHI). URL: https://www . ofgem.gov.uk/environmental-programmes/domestic-rhi. accessed: 0408-2020.

Orozaliev, J., Werner, F., Vajen, K., 2017. Learning curve of solar thermal heating systems, in: Proceedings Solar World Congress/IEA SHC Conference.

Parliament of the United Kingdom, 2008. Climate Change Act 2008. URL: https://www.legislation.gov.uk/ukpga/2008/27/contents.

Parliament of the United Kingdom, 2019. Climate Change Act 2008. URL: https://www.legislation.gov.uk/ukdsi/2019/9780111187654.

Qiu, Y., Anadon, L.D., 2012. The price of wind power in China during its expansion : Technology adoption, learning-by-doing, economies of scale, and manufacturing localization. Energy Economics 34, 772-785.

Renaldi, R., Friedrich, D., 2019. Techno-economic analysis of a solar district heating system with seasonal thermal storage in the UK. Applied Energy 236, $388-400$.

Renaldi, R., Kiprakis, A., Friedrich, D., 2017. An optimisation framework for thermal energy storage integration in a residential heat pump heating system. Applied energy 186, 520-529.

Rubin, E.S., Azevedo, I.M.L., Jaramillo, P., Yeh, S., 2015. Review article A review of learning rates for electricity supply technologies. Energy Policy 86, $198-218$.

Schmidt, O., Hawkes, A., Gambhir, A., Staffell, I., 2017. The future cost of electrical energy storage based on experience rates. Nature Energy 2, 17110.

Sovacool, B.K., Martiskainen, M., 2020. Hot transformations: Governing rapid and deep household heating transitions in China, Denmark, Finland and the United Kingdom. Energy Policy 139, 111330.

Taylor, M., Nemet, G., Colvin, M., Begley, L., Wadia, C., Dillavou, T., 2007. Government Actions and Innovation in Clean Energy Technologies: The Cases of Photovoltaic Cells, Solar Thermal Electric Power, and Solar Water Heating. Technical Report. (CEC)-500-2007-012. Sacramento: California Energy Commission.

The Internet Archive, 2019. Internet Archive: Wayback Machine. URL: https: //archive.org/web/. accessed: 2019-05-30. 
Van Buskirk, R., Kantner, C., Gerke, B., Chu, S., 2014. A retrospective investigation of energy efficiency standards: policies may have accelerated long term declines in appliance costs. Environmental Research Letters 9, 114010.

Wei, M., Smith, S.J., Sohn, M.D., 2017. Non-constant learning rates in retrospective experience curve analyses and their correlation to deployment programs. Energy Policy 107, 356-369.

Weiss, M., Dittmar, L., Junginger, M., Patel, M.K., Blok, K., 2009. Market diffusion, technological learning, and cost-benefit dynamics of condensing gas boilers in the Netherlands. Energy Policy 37, 2962-2976.

Weiss, W., Spörk-Dür, M., 2017. Solar Heat Worldwide. URL: https://www . iea-shc.org/solar-heat-worldwide-past. accessed: 25-08-2020.

Wright, T.P., 1936. Factors affecting the cost of airplanes. Journal of the Aeronautical Sciences 3, 122-128.

Zheng, C., Kammen, D.M., 2014. An innovation-focused roadmap for a sustainable global photovoltaic industry. Energy Policy 67, 159-169. 